\title{
Long-Term Existence of SARS-CoV-2 in COVID-19 Patients: Host Immunity, Viral Virulence, and Transmissibility
}

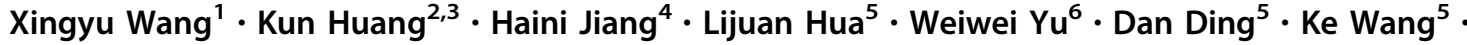 \\ Xiaopan $\mathrm{Li}^{5} \cdot$ Zhong Zou ${ }^{2,3}$ (D) Meilin $\mathrm{Jin}^{2,3}$ (D) Shuyun $\mathrm{Xu}^{5}$ (1)
}

Received: 13 August 2020/Accepted: 10 September 2020/Published online: 6 November 2020

(C) Wuhan Institute of Virology, CAS 2020

\begin{abstract}
COVID-19 patients can recover with a median SARS-CoV-2 clearance of 20 days post initial symptoms (PIS). However, we observed some COVID-19 patients with existing SARS-CoV-2 for more than 50 days PIS. This study aimed to investigate the cause of viral clearance delay and the infectivity in these patients. Demographic data and clinical characteristics of 22 long-term COVID-19 patients were collected. The median age of the studied cohort was $59.83 \pm 12.94$ years. All patients were clinically cured after long-term SARS-CoV-2 infection ranging from 53 to 112 days PIS. Peripheral lymphocytes counts were normal. The ratios of interferon gamma (IFN- $\gamma$ )-secreting cells to total $\mathrm{CD}^{+}$and $\mathrm{CD}^{+}$cells were normal as $24.68 \% \pm 9.60 \%$ and $66.41 \% \pm 14.87 \%$ respectively. However, the number of IFN$\gamma$-secreting NK cells diminished $(58.03 \% \pm 11.78 \%)$. All patients presented detectable $\mathrm{IgG}$, which positively correlated with mild neutralizing activity (Mean value neutralisation antibodies titers $=157.2, P=0.05$ ). No SARS-CoV-2 virus was isolated in Vero E6 cells inoculated with nasopharyngeal swab samples from all patients 50 days PIS, and the cytopathic effect was lacking. But one sample was positive for SARS-CoV-2 nucleic acid test in cell supernatants after two passages. Genome sequencing revealed that only three synonymous variants were identified in spike protein coding regions. In conclusion, decreased IFN- $\gamma$ production by NK cells and low neutralizing antibodies might favor SARS-CoV-2 long-term existence. Further, low viral load and weak viral pathogenicity were observed in COVID-19 patients with long-term SARSCoV-2 infection.
\end{abstract}

Keywords SARS-CoV-2 $\cdot$ Long-term $\cdot$ Neutralization antibody $\cdot$ Lymphocyte functionality $\cdot$ Viral pathogenicity

Electronic supplementary material The online version of this article (https://doi.org/10.1007/s12250-020-00308-0) contains supplementary material, which is available to authorized users.

Shuyun $\mathrm{Xu}$

sxu@hust.edu.cn

Meilin Jin

jm18328@126.com

$\square$ Zhong Zou

zz19841024@126.com

1 Division of Cardiothoracic and Vascular Surgery, Tongji Hospital, Tongji Medical College, Huazhong University of Science and Technology, Wuhan 430030, China

2 State Key Laboratory of Agricultural Microbiology, Huazhong Agricultural University, Wuhan 430070, China

3 College of Veterinary Medicine, Huazhong Agricultural University, Wuhan 430070, China
4 Medical Affairs Office, Tongji Hospital, Tongji Medical College, Huazhong University of Science and Technology, Wuhan 430030, China

5 Department of Respiratory and Critical Care Medicine, Key Laboratory of Pulmonary Diseases of Health Ministry, Tongji Hospital, Tongji Medical College, Huazhong University of Science and Technology, Wuhan 430030, China

6 General Department, Tongji Hospital, Tongji Medical College, Huazhong University of Science and Technology, Wuhan 430030, China 


\section{Introduction}

The ongoing coronavirus disease (COVID-19) pandemic caused by severe acute respiratory syndrome coronavirus 2 (SARS-CoV-2) remains a substantial threat to public health. Most COVID-19 patients recover with complete SARS-CoV-2 clearance and are released from quarantine (Wang et al. 2020). A previous study showed that the median and the longest duration of SARS-CoV-2 clearance were 20 days and 37 days from illness onset, respectively (Zhou et al. 2020), with a duration over 30 days categorized as prolonged viral shedding (Jin et al. 2020). However, we observed a cluster of COVID-19 patients with long-term SARS-CoV-2 infection extending to 50 days from onset. Although clinically cured with an absence of related symptoms and massively improved chest radiology, these patients persistently tested positive for SARS-CoV-2 nucleic acids in upper respiratory samples, and were thus subjected to quarantine. It is unclear why viruses could not be fully cleared in these individuals.

The host immune system is involved in the pathogenesis of COVID-19. SARS-CoV-2 infection triggers $\mathrm{T}$ and $\mathrm{B}$ cell-mediated immune responses, which are capable of eliminating the virus and resolving the infection (Zhang et al. 2020). $\mathrm{CD}^{+} \mathrm{T}$ cells and natural killer (NK) cells are important for directly attacking and killing virus-infected cells. SARS-CoV-2-specific neutralizing antibodies produced by $\mathrm{B}$ cells can neutralize viruses, thereby blocking SARS-CoV-2 infection, whereas $\mathrm{CD}^{+}{ }^{+} \mathrm{T}$ cells are crucial to prime both $\mathrm{CD}^{+} \mathrm{T}$ cells and B cells (Ni et al. 2020; Tay et al. 2020; Zhang et al. 2020). However, in some COVID-19 patients, a dysfunctional immune response occurs, which can cause severe lung and even systemic pathology (Tay et al. 2020). Lymphocytopenia is a prominent clinical feature of COVID-19 patients, where $\mathrm{CD} 4^{+}$and $\mathrm{CD} 8^{+} \mathrm{T}$ cells are suppressed, thereby disabling viral clearance, particularly in severe and critical cases (Ni et al. 2020). Moreover, Chen et al. demonstrated that B cells and NK cells were less suppressed in infected patients (Chen et al. 2020). Nevertheless, it remains unknown whether COVID-19 patients with long-term SARS-CoV-2 infection had a dysfunctional immune response, which delayed viral clearance.

The presence of SARS-CoV-2 nucleic acids in the respiratory tract indicates an infective COVID-19 patient who needs quarantine. It has been shown that virus transmission begins 2-3 days prior to the appearance of the first symptoms and peaks at 0.7 days before symptom onset, pointing to the markedly enhanced virulence ( $\mathrm{He}$ et al. 2020). Yet, in asymptomatic individuals carrying SARS$\mathrm{CoV}-2$, transmissibility may be weak and last for as long as 21 days (Gao et al. 2020; Hu et al. 2020). However, it remains unknown if virulence is altered in long-term COVID-19 patients and whether they are contagious or not.

In this study, we analysed host immunity, cultured and isolated SARS-CoV-2, and performed genome sequencing in COVID-19 patients with long-term infection. We aimed to investigate the reasons of viral clearance delay and infectivity and to ultimately facilitate improved management of COVID-19 patients.

\section{Methods and Materials}

\section{Study Design and Participants}

In this retrospective, single-centre study, we recruited 22 laboratory-confirmed COVID-19 patients with long-term existence of SARS-CoV-2 nucleic acid infection. They were quarantined at Tongji Hospital, Tongji Medical College of Huazhong University of Science and Technology, in Wuhan, China. Demographic data, comorbidities, symptoms, disease severity, imaging examinations, and other laboratory findings were collected from electronic medical records using data collection forms. Another physician on our team reviewed the data independently.

\section{Peripheral Lymphocyte Count and Functionality Assessment}

Peripheral blood was collected and heparinized. The absolute and percentage numbers of $\mathrm{CD}^{+}$and $\mathrm{CD} 8^{+} \mathrm{T}$ cells, B cells, and NK cells were determined by using TruCOUNT tubes and BD Multitest 6-color TBNK Reagent Kit (BD Biosciences) according to the manufacturer's instructions as previously described (Mazzoni et al. 2020). In brief, $50 \mu \mathrm{L}$ of whole blood was labelled with 6-color TBNK antibody cocktail for $15 \mathrm{~min}$ in room temperature, followed by adding $450 \mu \mathrm{L}$ of FACS Lysing Solution. Samples were then analysed with a FACSCanto flow cytometer using FACSCanto clinical software (BD Biosciences). Cells with high CD45 expression and low side scatter were gated as lymphocytes. TruCOUNT beads were gated based on side scatter and fluorescence intensity. $\mathrm{CD}^{+}$cells in lymphocyte gate were defined as total $\mathrm{T}$ cells. $\mathrm{CD}^{+}{ }^{+} \mathrm{T}$ cells or $\mathrm{CD} 8^{+} \mathrm{T}$ cells, $\mathrm{B}$ cells, and $\mathrm{NK}$ cells were defined as $\mathrm{CD}^{+} \mathrm{CD}^{-}$or $\mathrm{CD}^{+} \mathrm{CD}^{-}$cells in $\mathrm{CD}^{+}$cells, $\mathrm{CD} 19^{+}$, and $\mathrm{CD} 16^{+} \mathrm{CD}^{+} 6^{+}$cells in $\mathrm{CD}^{-}$ cells, respectively.

PMA/ionomycin-stimulated lymphocyte functionality assay was performed as described preciously (Zhang et al. 2019; Mazzoni et al. 2020; Zheng et al. 2020). We diluted $100 \mu \mathrm{L}$ of whole blood with $400 \mu \mathrm{L}$ of IMDM medium and stimulated with Leukocyte Activation Cocktail for $4 \mathrm{~h}$ (containing PMA, ionomycin and brefeldin A, BD 
GolgiPlug). The cells were labelled with monoclonal antibodies (anti-CD3, anti-CD4, anti-CD8, and anti-CD56), fixed and permeabilized, stained with intracellular antiIFN- $\gamma$ (catalog 554702) antibody, and analysed by flow cytometry.

\section{Nucleic Acid Extraction and RT-PCR for SARS- CoV-2}

Nasopharyngeal swab specimens were collected. RNA was extracted with QIAamp vRNA Minikit (Qiagen, Hilden, Germany), and SARS-CoV-2-specific viral RNA was detected with the Novel Coronavirus 2019-nCoV Nucleic Acid Detection Kit (Real Time RT-PCR) (GeneDx, Shanghai, China), which targeted the $N$ and ORFlab genes, according to the manufacturer's instructions. A cycle threshold $(\mathrm{Ct})$ value of 40 was used as the cut-off value for positive tests.

The amplification procedure was set at $94^{\circ} \mathrm{C}$ for $2 \mathrm{~min}$, 40 cycles of $94^{\circ} \mathrm{C}$ for $15 \mathrm{~s}$, annealing for $30 \mathrm{~s}$ and $68^{\circ} \mathrm{C}$ for $1 \mathrm{~min}$, followed by $68^{\circ} \mathrm{C}$ for $5 \mathrm{~min}$. The annealing temperatures were $55^{\circ} \mathrm{C}$ for the whole $S$ gene both for the first and second round. The final amplification products of $S$ gene were sequenced with nested PCR. Sequence data discovered in this study have been deposited in GISAID (https://www.gisaid.org/) with the accession number EPI_ISL_470802.

Nested PCR was carried out using $2 \times$ TransStart FastPFU Fly PCR SuperMix of the whole $S$ gene. Primer pairs, CoV-F1 (5'-GGTTGGGATTATCCTAAATGTGA-3') and CoV-R (5'-GCATCGTCAGAGAGTATCATCAT- $\left.3^{\prime}\right)$, and CoV-F2 (5'-GATTATCCTAAATGTGATAGAGC-3') and CoV-R were used, respectively.

The amplification procedure was set at $94^{\circ} \mathrm{C}$ for $2 \mathrm{~min}$, 40 cycles of $94^{\circ} \mathrm{C}$ for $15 \mathrm{~s}$, annealing for $30 \mathrm{~s}$ and $68^{\circ} \mathrm{C}$ for $1 \mathrm{~min}$, followed by $72^{\circ} \mathrm{C}$ for $5 \mathrm{~min}$.

\section{Detection of SARS-CoV-2 Specific Antibody and Virus Neutralization Test (VNT)}

For measurement of IgM and IgG against SARS-CoV-2, plasma samples were collected from COVID-19 patients when the final positive SARS-CoV-2 test was present. IgM and IgG antibodies were quantified using the chemiluminescent microparticle immunoassay (CMIA) technique, according to the manufacturer guide (2019-nCoV antibody detection kit, InnoDx, Xiamen, China). Briefly, the sample, SARS-CoV-2 antigen-coated paramagnetic microparticles, and assay dilutes were combined and incubated, during which the IgM and IgG antibodies bound to the SARSCoV-2 antigen-coated microparticles. The mixture was then washed, and anti-human IgM or IgG acridinium-labelled conjugate was added to create a reaction mixture, followed by incubation. Following a wash cycle, PreTrigger and Trigger solutions were added. The chemiluminescent reaction was then measured as a relative light unit (RLU) detected by system optics, which was in a direct relationship with the amount of IgM and IgG antibodies against SARS-CoV-2 in the sample.

For the virus neutralization test, plasma samples were heat-inactivated by incubation at $56{ }^{\circ} \mathrm{C}$ for $30 \mathrm{~min}$. Each plasma sample was serially diluted with Dulbecco's modified Eagle medium (DMEM) by twofold or threefold according to the OD value and sample quality mixed with an equal volume of diluted virus. The mixture was incubated at $37{ }^{\circ} \mathrm{C}$ for $1 \mathrm{~h}$. Vero E6 (ATCC CRL-1586) cells in 24-well plates were inoculated with the sera-virus mixture at $37{ }^{\circ} \mathrm{C} ; 1 \mathrm{~h}$ later, the mixture was replaced with DMEM containing $2.5 \% \mathrm{FBS}$ and $0.8 \%$ carboxymethylcellulose. The plates were fixed with $8 \%$ paraformaldehyde and stained with $0.5 \%$ crystal violet 3 days later. All samples were tested in duplicate, and neutralization titres were defined as the plasma dilution resulting in a plaque reduction of at least $50 \%$.

\section{Virus Isolation}

Fresh nasopharyngeal swab specimens collected from laboratory-confirmed COVID-19 patients in viral transport media were used as the inoculum for virus isolation. Briefly, Vero E6 cells were cultured for $24 \mathrm{~h}$ in a 24-well plate format before inoculation. The culture medium was the minimal essential medium containing $2 \%$ foetal bovine serum, 100 units $/ \mathrm{mL}$ penicillin, and $100 \mu \mathrm{g} / \mathrm{mL}$ streptomycin. The swab specimens were centrifuged at $5000 \mathrm{rpm}$ for $10 \mathrm{~min}$ at $4{ }^{\circ} \mathrm{C}$ in a benchtop centrifuge, and the supernatant was separated and inoculated on Vero E6 cells in alternative wells of the 24-well plate. After two hours of incubation for adsorption in a $37{ }^{\circ} \mathrm{C}$ incubator containing $5 \% \mathrm{CO}_{2}$, fresh virus growth medium was added to a final volume of $1 \mathrm{~mL}$ and then incubated in a $37{ }^{\circ} \mathrm{C}$ incubator containing $5 \% \mathrm{CO}_{2}$ for six days. The presence of cytopathic effect (CPE) was monitored daily.

\section{Virus Genome Sequencing}

The virus genome was sequenced by two different approaches, (1) untargeted metatranscriptome sequencing on the BGI MGISEQ-2000 sequencing platforms, and (2) Sanger sequencing of the spike region of the virus genome. For the metatranscriptome approach, total RNA was extracted from nasopharyngeal swab specimens, followed by synthesis of double-strand cDNA. cDNA were then subjected to concentration and quality measurement with the Agilent Bioanalyzer 2100 and Qubit. DNA nanoball (DNB)-based libraries were constructed following the 
manufacturer's protocol. The libraries were then sequenced on the MGISEQ-2000 platform with a sequencing length of paired-end $150 \mathrm{bp}$. For the multiplex PCR approach, we designed PCR primers that fully cover the whole virus genome to perform the amplicon sequencing. The PCR products were collected and quantified, followed by MGISEQ-2000 DNB-based library preparation and sequencing. The samples with the highest $\mathrm{Ct}$ value were reverse transcribed with random primers, using the PrimeScript RT reagent Kit (TaKaRa, Dalian, China). Nested PCR was carried out by using $2 \times$ TransStart FastPFU Fly PCR SuperMix to obtain the whole spike gene.

\section{Sequencing Data Analysis}

Sequencing adaptors were removed from the raw reads, and reads were filtered for quality using Trimmomatic. The clean reads were then mapped to the host genome (NCBI assembly accession GCF_000181335.3) using Bowtie2, and only reads that could not be mapped to the monkey genome were retained for mapping against the virus genome (NCBI MN908947.3). Based on the virus genome mapping results, reference-based assembly of the mapping reads was performed. Consensus sequences were generated using Samtools 1.9 and Bcftools 1.10.2.

Routine sequence management and analysis were carried out using DNAStar. Sequence alignment of SARSCoV-2 with reference sequences was carried out with MEGA software (version 6.0). The codon alignments of the full-length $S$ and $R d R p$ gene sequences were converted from the corresponding protein alignments by PAL2NAL (v.14); the protein alignments were created by Clustal Omega (v.1.2.4) using default parameters. Maximum likelihood phylogenetic trees were generated using RAxML (v.0.9.0) with the GTR + G substitution model and 1000 bootstrap replicates. The sequences obtained in this study were deposited in GISAID (https://www.gisaid. org/).

\section{Statistical Analysis}

Analyses was performed using Graph Pad Prism (GraphPad Software, San Diego, CA, USA). All continuous variable data were tested for normality using a ShapiroWilk test. Continuous data was presented as mean \pm SD or median (IQR) in case of skewed data. Categorical outcomes were given as absolute and relative frequencies (\%). Pearson's correlation coefficients were calculated. $P<0.05$ indicates statistical significance.

\section{Results}

\section{Demographics and Clinical Characteristics}

The mean age of the cohort was 59.83 years, and $54.55 \%$ were male. Non-severe patients represented $45.45 \%$ of the total, and the rest $(54.55 \%)$ were severe, in accordance with the Diagnosis and Treatment Program of COVID-19 ( $7^{\text {th }}$ edition). Hypertension was the leading pre-existing disease $(45.45 \%)$, followed by diabetes $(40.91 \%)$, chronic respiratory diseases $(13.64 \%)$, chronic renal disease $(13.64 \%)$, coronary heart disease $(9.09 \%)$, cancer $(9.09 \%)$ and chronic hepatitis $(4.55 \%)$. All patients $(100 \%)$ were clinically cured, presenting no symptoms and significantly improved chest computed tomography scan. Only one patient exhibited mild somnolence (Table 1).

\section{Evolutionary Course, Conversion, and Viral Load in Long-Term SARS-CoV-2 Infection}

All 22 of the studied patients were visibly positive for SARS-CoV-2 nucleic acids in nasopharyngeal swab specimens 50 days after initial symptoms. The final positive result was observed and demonstrated in a timeframe of 50 to 120 days post initial symptoms (Fig. 1A). The positive rate gradually declined to $86.36 \%$ at 70 days, $36.36 \%$ at 80 days, and $4.55 \%$ at 100 days post initial symptoms. Such decline became significant after 75 days post initial symptoms (positive rate 59.09\%), and dropped to $0 \%$ after 110 days. In turn, patients were consistently converted to negative for SARS-CoV-2 nucleic acid, and the conversions were mainly centralized between 70 and 90 days, with the latest negative result pronounced 115 days post initial symptoms (Fig. 1B).

Meanwhile, we analysed SARS-CoV-2 load in nasopharyngeal swab specimens by RT-PCR. Ct values were used as a relative standard for SARS-CoV-2 RNA expression, with lower $\mathrm{Ct}$ values corresponding to higher viral copy numbers. For each specimen, SARS-CoV-2 was considered positive if the $\mathrm{Ct}$ value of either the ORFIab gene or the $N$ gene was less than 40 . The $\mathrm{Ct}$ values of the latest positive SARS-CoV-2, categorized to ORFlab (Ct value $36.40 \pm 3.36)$ and $N(\mathrm{Ct}$ value $36.06 \pm 3.23)$ were demonstrated in Fig. 1C, in an observational period of 50-120 days after symptom onset. Eighteen patients $(81.8 \%)$ were double positive for both genes, while single positive either for the ORFIab gene or the $N$ gene were 3 $(13.6 \%)$ or $1(4.60 \%)$, respectively. 
Table 1 Demographics and clinical characteristics of studied patients.

\begin{tabular}{|c|c|}
\hline \multicolumn{2}{|l|}{ Characteristics } \\
\hline Age-years, mean $\pm \mathrm{SD}$ & $59.83 \pm 12.94$ \\
\hline \multicolumn{2}{|l|}{ Gender-n/N (\%) } \\
\hline Male & $12 / 22(54.55)$ \\
\hline Female & $10 / 22(45.45)$ \\
\hline \multicolumn{2}{|l|}{ Underlying diseases— $n / N(\%)$} \\
\hline Hypertension & $10 / 22(45.45)$ \\
\hline Diabetes & $9 / 22(40.91)$ \\
\hline Chronic respiratory diseases & $3 / 22(13.64)$ \\
\hline Chronic renal disease & $3 / 22(13.64)$ \\
\hline Coronary heart disease & $2 / 22(9.09)$ \\
\hline Cancer & $2 / 22(9.09)$ \\
\hline Chronic hepatitis & $1 / 22(4.55)$ \\
\hline \multicolumn{2}{|l|}{ Disease Severity of COVID-19-n/N (\%) } \\
\hline Non-severe & $12(54.55)$ \\
\hline Severe & $10(45.45)$ \\
\hline \multicolumn{2}{|l|}{ Initial symptoms-n/N (\%) } \\
\hline Cough & $20 / 22(90.90)$ \\
\hline Fever & $18 / 22(81.82)$ \\
\hline Fatigue & $12 / 22(54.55)$ \\
\hline Dyspnea & $8 / 22(36.36)$ \\
\hline Chest tightness & $7 / 22(31.82)$ \\
\hline Myalgia & $4 / 22(18.18)$ \\
\hline Diarrhoea & $2 / 22(9.09)$ \\
\hline Nausea or vomit & $1 / 22(4.55)$ \\
\hline \multicolumn{2}{|l|}{ Clinical outcomes $\dagger-n / N(\%)$} \\
\hline Symptoms alleviated & $22(100)$ \\
\hline Presented symptoms & $1(4.55)$ \\
\hline Chest computed tomography improved or almost normal & $22 / 22(100.00)$ \\
\hline Freedom of oxygen treatment & $22 / 22(100.00)$ \\
\hline Highest body temperature within $72 \mathrm{~h}$ prior to sampling $\left({ }^{\circ} \mathrm{C}\right)$ & $36.64 \pm 0.38$ \\
\hline
\end{tabular}

\section{Long-Standing SARS-CoV-2-Induced Host Immune Response}

To explore the immune response in COVID-19 patients with long-term SARS-CoV-2 infection, the peripheral blood subgroup of lymphocytes and IFN- $\gamma$-secreting $\mathrm{T}$ cells were assessed at the time of latest positive SARS$\mathrm{CoV}-2$ tests. IFN- $\gamma$ producing capability can be used as a marker of lymphocyte function. The counts of total $\mathrm{T}$ lymphocytes, total B lymphocytes (tBL), $\mathrm{CD}^{+} \mathrm{T}$ cells, $\mathrm{CD}^{+} \mathrm{T}$ cells, and NK cells were $1184 \pm 297.2 / \mu \mathrm{L}$, $170.6 \pm 75.29 / \mu \mathrm{L}, 709.3 \pm 237.7 / \mu \mathrm{L}, 413.9 \pm 192.8 / \mu \mathrm{L}$, and $402.7 \pm 537.7 / \mu \mathrm{L}$, respectively (Fig. 2A). Functionality assessment disclosed that the ratios of IFN- $\gamma$-secreting cells to total $\mathrm{CD}^{+}$and $\mathrm{CD}^{+} \mathrm{T}$ cells were $24.68 \% \pm 9.60 \%$ and $66.41 \% \pm 14.87 \%$, respectively, which were generally in the normal range $(14.54 \%$ $36.96 \% ; 34.93 \%-87.95 \%)$. IFN- $\gamma$-secreting NK cells were $58.03 \% \pm 11.78 \%$, lower than the given range $(61.2 \%$ 92.65\%) (Fig. 2B).

Next, we detected SARS-CoV-2-specific antibodies and their SARS-CoV-2 neutralizing activity, which was evaluated by neutralization antibody titres. Plasma samples were collected upon the time of latest positive SARS-CoV-2 test. All patients generated moderate IgG titres (94.41, 83.46-114.40 mg/mL) against SARS-CoV-2. Also, SARSCoV-2-specific IgM $(5.57, \quad 1.75-17.40 \mathrm{mg} / \mathrm{mL})$ was detectable but deemed negative according to the user guide 
A
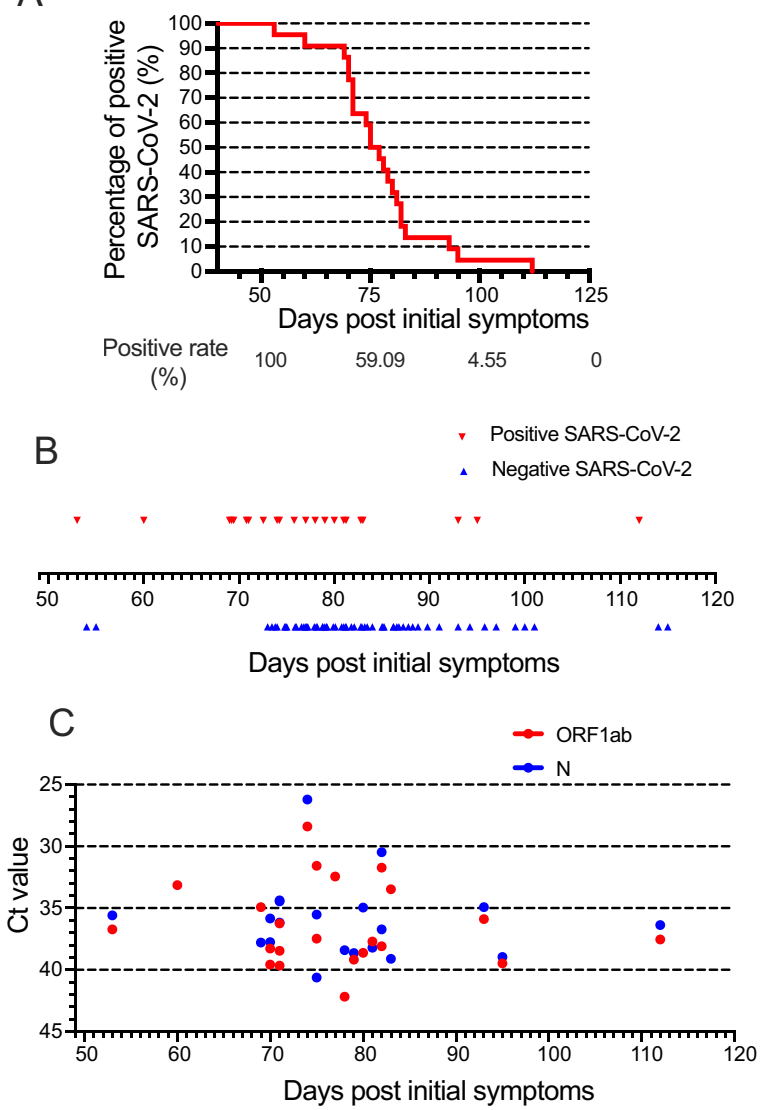

Fig. 1 Evolutionary course, conversion, and viral load of long-term SARS-CoV-2 patients. Positive rate of latest SARS-CoV-2 (A), negative conversion (B), and $\mathrm{Ct}$ value of $O R F 1 a b$ and $N$ for latest positive SARS-CoV-2 (C) in studied 22 patients from 50 to 120 days post initial symptoms.

of the test $(<10 \mathrm{mg} / \mathrm{mL})$ in the same time point (Fig. $2 \mathrm{C}$ ). The mean value of SARS-CoV-2 neutralizing activity of the 22 studied patients was 157.2 , of which 5 exhibited no neutralization antibody (NAb) (Fig. 2C). The production of SARS-CoV-2-specific NAb was positively correlated to the titres of $\operatorname{IgG}\left(P=0.054, \mathrm{R}^{2}=0.1738\right.$, Fig. 2D), but had no correlation to the B cell $(P=0.5932)$ and $\mathrm{CD}^{+}{ }^{+} \mathrm{T}$ cell $(P=0.6184)$ counts, as shown in Fig. $2 \mathrm{E}$ and $2 \mathrm{~F}$.

\section{Correlation of SARS-CoV-2 Load and Immune Reaction}

We also analysed whether the SARS-CoV-2 load was correlated to the immune response (Fig. 3). The expression of the $N$ gene was found to be positively correlated to the NK cells $\left(P=0.0023, \mathrm{R}^{2}=0.4105\right.$, Fig. $\left.3 \mathrm{E}\right)$, but not for the other lymphocyte subsets. Furthermore, the OFRlab gene was not correlated to any lymphocyte subsets, neither for cell count, nor for functionality (Fig. 3A-3H).

\section{SARS-CoV-2 Isolation and Sequencing}

To investigate whether SARS-CoV-2 virulence had altered, virus isolation was performed with Vero E6 cells from nasopharyngeal swab specimens 50 days after initial symptoms in COVID-19 patients. We were not able to isolate SARS-CoV-2 and did not observe a cytopathic effect (Fig. 4A). However, only one sample from one COVID-19 patient (Patient \#4) was positive for SARSCoV-2 nucleic acid in cell supernatants from two passages, with $\mathrm{Ct}$ values gradually increasing during cell passages (Fig. 4B). However, further passages of the virus in Vero E6 cells were unsuccessful.

Metatranscriptome sequencing was performed on the abovementioned positive sample to analyse the virus genome. Amplicon sequencing of the multiplex PCR products generated extra $65,847,006$ reads, 69,506 of which were SARS-CoV-2 reads. Those SARS-CoV-2 reads together covered 11,160 nucleotides (37.5\% of the genome) of the virus genome (Fig. 4C). Eleven consensus sequences longer than $200 \mathrm{bp}$ were obtained, with a total length of $7032 \mathrm{nt}(23.6 \%$ of the genome) and length ranging from $225 \mathrm{nt}$ to $1500 \mathrm{nt}$. No variant in the covered virus genome region was observed. One of the consensus sequences had an overlap of 354 nucleotides with the receptor-binging domain of the spike protein coding sequence, showing $100 \%$ identity with the reference of Wuhan-Hu-1. Next, nested-PCR assays targeting the spike gene of SARS-CoV2 were also performed on this sample, and the amplified fragments were sequenced. Full-genome sequences of the $S$ gene, named hCov-19/Wuhan/Tongji-04-2/2020, were submitted to GISAID and are available under accession numbers EPI_ISL_4470802/2020-04-20. To better understand the evolutionary relationships of hCov-19/Wuhan/ Tongji-04-2/2020 in detail, phylogenetic analyses were conducted (Supplementary Figure S1). The $S$ gene of hCoV-19/Wuhan/Tongji-04-2/2020 were more closely related to EPI_ISL_480345 and EPI_ISL_478457, while EPI_ISL_434534 was more distant (Supplementary Figure S1). Compared to the first released genome (Wuhan$\mathrm{Hu}-1$ ), a total of only 3 synonymous variants were identified in spike protein-coding regions.

\section{Discussion}

In this study, we analysed the immunological parameters, isolated viruses, and performed whole-genome sequencing of SARS-CoV-2 in long-term COVID-19 patients. We found that although the numbers of lymphocytes were normal, both IFN- $\gamma$-expressing NK cells and the titres of SARS-CoV-2-specific neutralizing antibodies were at a 

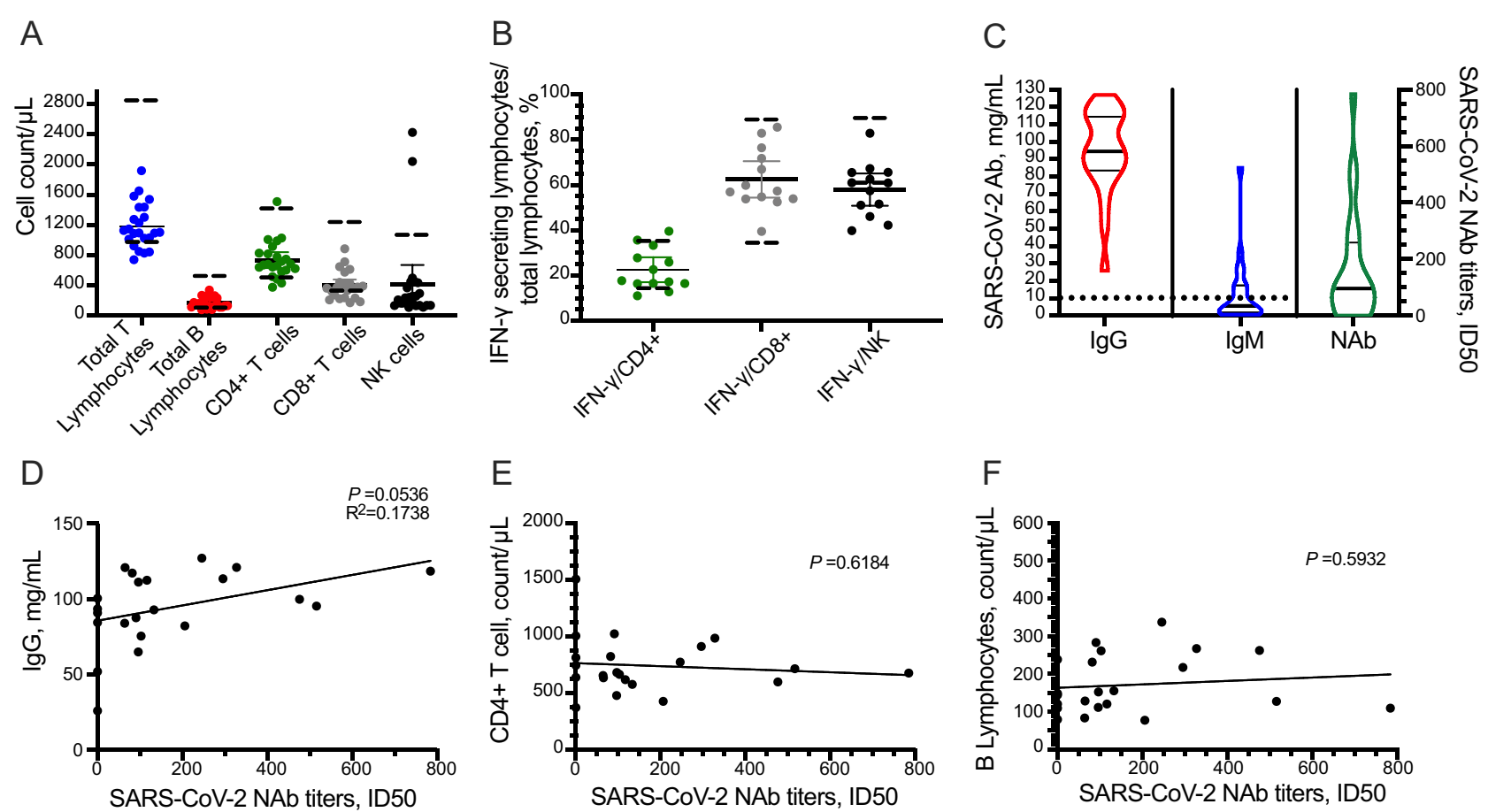

Fig. 2 Long-standing SARS-CoV-2-induced host immune response. Peripheral blood lymphocyte counts (A). Lymphocyte functionality assessed by IFN- $\gamma$ produced $\mathrm{CD} 4^{+} / \mathrm{CD}^{+} \mathrm{T}$ cells or NK cells $(\mathbf{B})$. Detection of SARS-CoV-2-specific IgM, IgG, and neutralizing
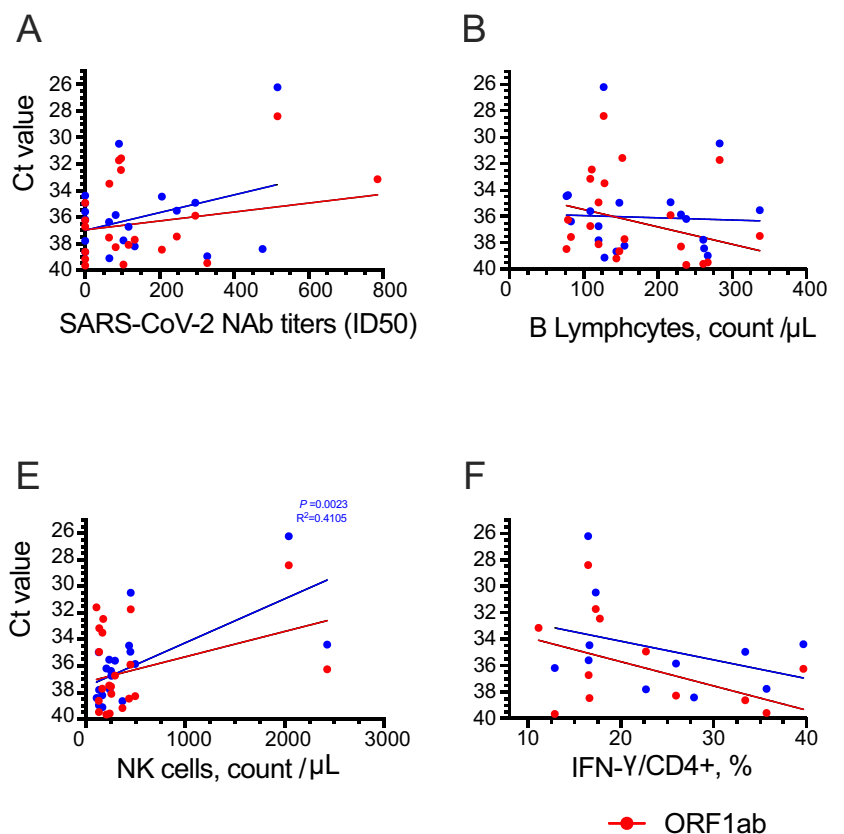

Fig. 3 Correlation of long existing SARS-CoV-2 load and immune reaction. Correlation of $\mathrm{Ct}$ value of ORFlab or $N$ and SARS-CoV-2 neutralizing antibody (A), B lymphocytes $(\mathbf{B}), \mathrm{CD}^{+} \mathrm{T}$ cell $(\mathbf{C})$,

low level. The SARS-CoV-2 was not successfully isolated nor the cytopathic effects were observed. The analysis of the virus genome from only one COVID-19 patient antibody (C). Correlation of SARS-CoV-2-neutralizing activity with $\mathrm{IgG}(\mathbf{D}), \mathrm{B}$ lymphocytes $(\mathbf{E})$, and $\mathrm{CD}^{+} \mathrm{T}$ cell $(\mathbf{F})$, respectively. Dashed lines represent the normal range of giving items.
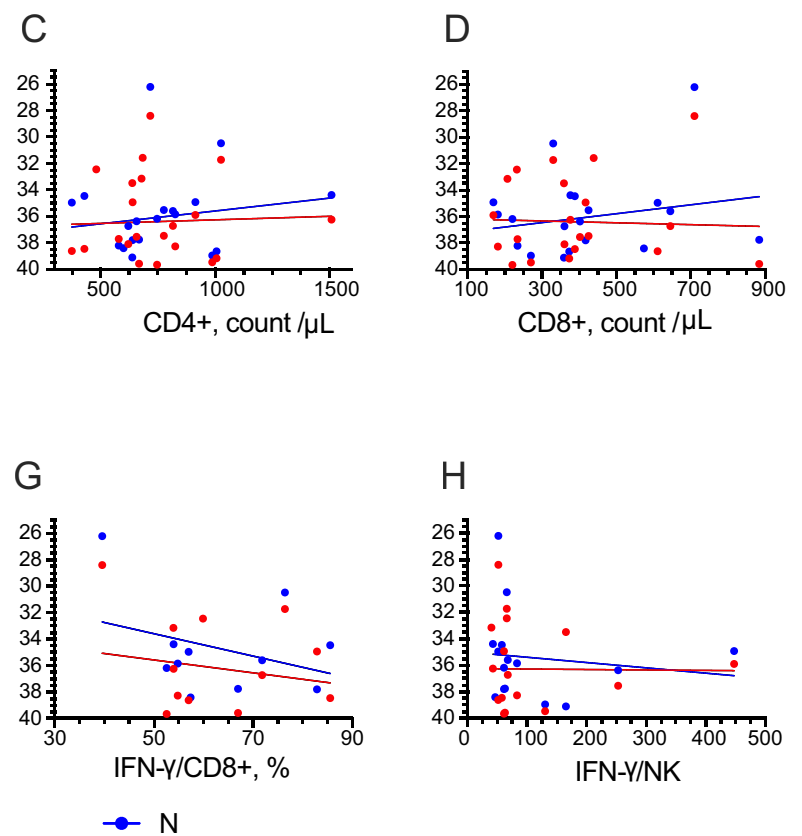

$\mathrm{CD}^{+} \mathrm{T}$ cell $(\mathbf{D}), \mathrm{NK}$ cell $(\mathbf{E}), \mathrm{IFN}-\gamma$ produced $\mathrm{CD} 4^{+} / \mathrm{CD} 8^{+} \mathrm{T}$ cell $(\mathbf{F}, \mathbf{G})$, or NK cell $(\mathbf{H})$.

revealed that three synonymous variants exist in the $\mathrm{S}$ gene-coding regions of SARS-CoV-2, compared to the first released genome. 
Fig. 4 The result of virus isolation and sequence. A Cytopathic effect of SARSCoV-2-infected cells. Vero E6 cells were inoculated with sample, and the cytopathic effect was not observed $72 \mathrm{~h}$ post-infection. B The $\mathrm{Ct}$ values of the sample from patient \#4. Vero E6 cells were inoculated with the sample for six days, and the supernatant was subjected to real-time RT-PCR detection with CFDA approved testing kits. The replication of the virus was indicated as $\mathrm{Ct}$ values. C NGS raw reads of patient \#4 mapped to the SARS$\mathrm{CoV}-2$ sequence. Reads coverage and sequencing depth of the metatranscriptome sequencing.
A

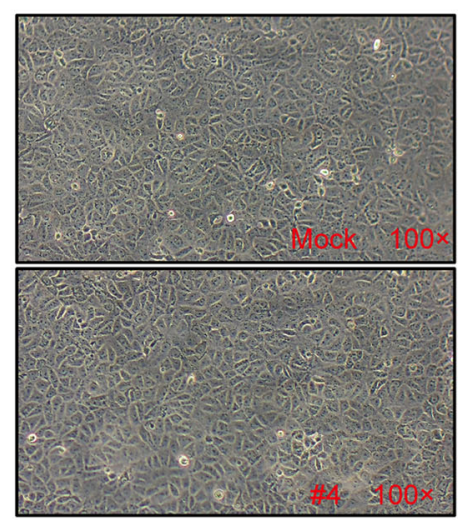

B

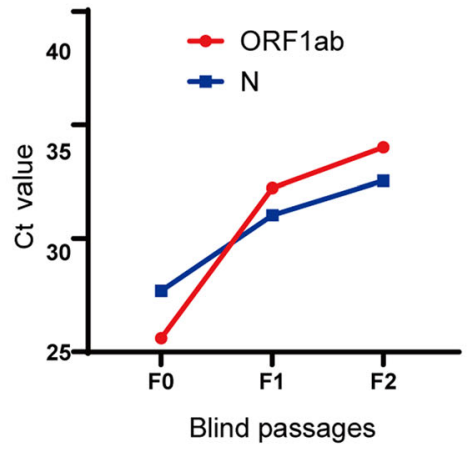

C
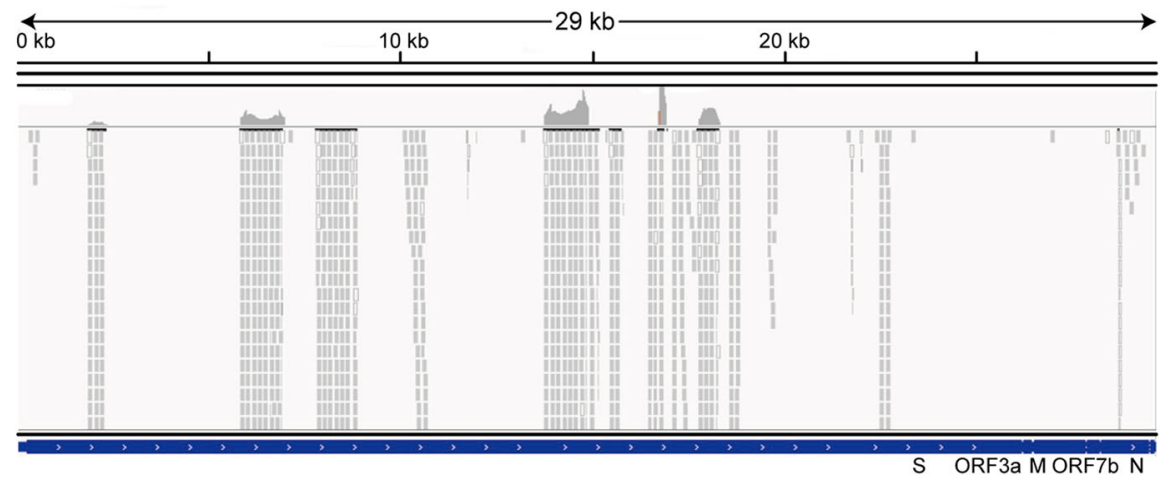

Twenty-two COVID-19 patients enrolled in this study showed long-term presence of SARS-CoV-2. They had shown clinical recovery with absence of related symptoms, massively improved or almost normal chest radiology, and did not need treatment anymore (Table 1). However, they displayed persistently detectable SARS-CoV-2 in the upper respiratory tract for more than 50 days PIS. The postsymptomatic median and the longest duration of detectable SARS-CoV-2 were 76 days and 112 days, respectively (Fig. 1A, 1B), which were much longer than in most recovered patients. Zhou et al. (Zhou et al. 2020) reported that the median and the longest duration of SARSCoV-2 clearance were 20 days and 37 days from illness onset, respectively. The interplay between host immune response and viruses in COVID-19 patients determines the development of the disease (Tay et al. 2020). It is therefore unclear whether host immunity or virus characteristics delay SARS-CoV-2 clearance in these COVID-19 patients.

In the present study, we first investigated the immune response of COVID-19 patients with long-term existence of SARS-CoV-2. Cytotoxic lymphocytes such as $\mathrm{CD}^{+} \mathrm{T}$ lymphocytes and NK cells are essential for the control of viral infections and affect viral clearance, which can be mediated by direct cytotoxicity or through the release of IFN- $\gamma$ (Rosen and Golden-Mason 2019; Ni et al. 2020; Padoan et al. 2020). The numbers of NK and $\mathrm{CD}^{+}{ }^{+} \mathrm{T}$ cells were decreased markedly, which was associated with exhausted function at the early stage of COVID-19 illness, but were restored after therapy (Padoan et al. 2020). In our study, SARS-CoV-2 load was positively correlated to total NK cells $\left(P=0.0012, \mathrm{R}^{2}=0.4155\right.$, Fig. $\left.3 \mathrm{E}\right)$, which suggested that viruses may induce the host to recruit more NK cells to eliminate viral infection. However, we found that the mean total number of NK cells was within the normal range, but $40.9 \%$ (9/22) COVID-19 patients showed a lower limit of normal value (Fig. 2A), and IFN- $\gamma$-expressing NK cells too were at the lower limit of normal value (Fig. 2B). These findings implied that NK cells may contribute to SARS-CoV-2 clearance, and the decrease in IFN- $\gamma$-expressing NK cells might delay viral clearance in COVID-19 patients with long-term existence of SARSCoV-2. This phenomenon also occurs in chronic hepatitis $\mathrm{C}$ virus infection, where decreased NK cell level and IFN- $\gamma$ production favour viral persistence (Tang et al. 2020).

As with any virus, the adaptive immune response plays a critical role in clearing SARS-CoV-2 infections and directly influences patients' clinical outcome. Recently, several studies characterizing adaptive immune responses to SARS-CoV-2 infection have reported that most COVID-19 convalescent individuals have detectable neutralizing antibodies, which correlate with the numbers of virusspecific T cells (Deshpande et al. 2020; Suthar et al. 2020; 
Thevarajan et al. 2020). Ling $\mathrm{Ni}$ and his colleagues demonstrated both $\mathrm{B}$ and $\mathrm{T}$ cells participate in immunemediated protection to SARS-CoV-2 infection in recovered patients (Ni et al. 2020). In our study, the total numbers of $\mathrm{CD} 8^{+} \mathrm{T}$ cells and IFN- $\gamma$-expressing $\mathrm{CD} 8^{+} \mathrm{T}$ cells were normal (Fig. 2A, 2B), and were not correlated to SARSCoV-2 load (Fig. 3D and 3G). CD4 ${ }^{+} \mathrm{T}$ cells are crucial to prime both $\mathrm{CD}^{+} \mathrm{T}$ cells and $\mathrm{B}$ cells $(\mathrm{Ni}$ et al. 2020; Tay et al. 2020). We found that $\mathrm{CD}^{+} \mathrm{T}$ cells and $\mathrm{B}$ cells showed similar results to $\mathrm{CD} 8^{+} \mathrm{T}$ cells (Figs. 2 and 3 ). These findings suggested that $\mathrm{CD} 4^{+} \mathrm{T}$ cells, $\mathrm{CD} 8^{+} \mathrm{T}$ cells, and $\mathrm{B}$ cells might not be dysfunctional in COVID-19 patients with long-term SARS-CoV-2 presence. However, further investigations to identify possible role of host factors in the delay of SARS-CoV-2 clearance are needed.

Next, we investigated whether SARS-CoV-2-specific antibodies produced by B cells contributed to delayed viral clearance in COVID-19 patients with long-term SARSCoV-2 infection. In COVID-19 patients, IgM antibodies appeared within a week post disease onset, and gradually decreased, whereas IgG antibodies were produced 10 days after infection and lasted for a longer time (Ni et al. 2020). Neutralizing antibodies block SARS-CoV-2 infection, and macrophages recognize neutralized viruses and clear them by phagocytosis (Tay et al. 2020). However, neutralizing antibodies titres varied in recovered COVID-19 patients, ranging from below detection $(<30)$ to 1936 , and virus neutralization deficiency occurred in some patients (Zhang et al. 2020). In our study, plasma SARS-CoV-2-specific IgM was close to normal (Fig. 2C). Although all patients generated plasma SARS-CoV-2-specific IgG at a relatively high level, neutralizing antibodies titres were modest, with $22.72 \%(5 / 22)$ patients not presenting any neutralizing activity (Fig. 2C). The low neutralizing antibodies had no correlation to B cells and CD4 ${ }^{+}$T cells (Fig. 2E, 2F). Taken together, these findings suggested that SARS-CoV-2-specific antibodies had low or even no virus neutralizing activity in COVID-19 patients with long-term SARS-CoV-2 infection. The reason nevertheless needs further investigation.

To investigate virus characteristics, we isolated viruses from nasopharyngeal swab specimens and performed whole-genome sequencing of SARS-CoV-2 in 22 COVID-19 patients with long-term SARS-CoV-2 infection. We found that the SARS-CoV-2 load was low in nasopharyngeal swab specimens (Fig. 1C). Although only one sample from one COVID-19 patient yielded positive SARS-CoV-2 nucleic acid results in the cell supernatants from two passages (Fig. 4B), SARS-CoV-2 could not be isolated successfully, and the cytopathic effects were not observed (Fig. 4A). Combined with the qRT-PCR results, we speculated that the lack of success was due to too low titres of SARS-CoV-2 in patients to be isolated effectively. Roman Wölfel and colleagues demonstrated that the success of virus isolation depended on viral load: samples that contained $<10^{6}$ copies per $\mathrm{mL}$ (or copies per sample) never yielded an isolate (Wolfel et al. 2020). These findings pointed out the insufficient viral load and weak viral pathogenicity in these patients. Such a phenomenon is identical to that in asymptomatic SARS-CoV-2 carriers (Gao et al. 2020; Hu et al. 2020). The analysis of the virus genome found that three synonymous variants were identified in the spike protein coding regions of SARS-CoV-2, compared to the first released genome (Wuhan-Hu-1) (Supplementary Figure S1 and Fig. 4). The obtained viral genome sequences suggested that the COVID-19 patients with long-term SARS-CoV-2 infection had no relationship with the virus itself.

Our study has a limitation. We failed to observe the dynamic changes in the viral load and the induced immune response, since the patients were referred from different hospitals for centralized quarantine with discontinuity of medical data.

In summary, we found that decreased IFN- $\gamma$ production by NK cells and the low neutralizing antibody count might favor SARS-CoV-2 long-term existence. However, the viral load was low, and viral pathogenicity was weak in COVID-19 patients with long-term SARS-CoV-2 infection. This study, to some extent, may provide additional concerns when handling patients clinically cured from COVID-19 but bearing long-term existed SARS-CoV-2.

Acknowledgements This work was support by National Natural Science Foundation of China under Grant (81800095) and Key Scientific and Technological Project of Hubei province (2020FCA004).

Author Contributions XW, ZZ, MJ and SX conceptualized the study; XW, KH, HJ., LH, WY, DD, KW, XL and ZZ acquisited and summarized the original data; XW, HJ, KH, ZZ analyzed the data; $\mathrm{XW}$; HJ; ZZ., KH and SX drafted the original manuscript; XW, ZZ, $\mathrm{MJ}$ and SX revised and edited the manuscript; XW, ZZ, MJ and SX supervised and managed the project; All authors have read and agreed to the published version of the manuscript.

\section{Compliance with Ethical Standards}

Conflict of interest The authors declare no conflict of interest.

Animal and Human Rights Statement The ethical committee of Tongji Hospital (file number TJ-IRB20200204) approved this study. All participates gave oral consent.

\section{References}

Chen G, Wu D, Guo W, Cao Y, Huang D, Wang H, Wang T, Zhang X, Chen H, Yu H, Zhang X, Zhang M, Wu S, Song J, Chen T, Han M, Li S, Luo X, Zhao J, Ning Q (2020) Clinical and immunological features of severe and moderate coronavirus disease 2019. J Clin Invest 130:2620-2629 
Deshpande GR, Sapkal GN, Tilekar BN, Yadav PD, Gurav Y, Gaikwad S, Kaushal H, Deshpande KS, Kaduskar O, Sarkale P, Baradkar S, Suryawanshi A, Lakra R, Sugunan AP, Balakrishnan A, Abraham P, Salve P, Team CS (2020) Neutralizing antibody responses to sars-cov-2 in covid-19 patients. Indian J Med Res 152:82-87

Gao M, Yang L, Chen X, Deng Y, Yang S, Xu H, Chen Z, Gao X (2020) A study on infectivity of asymptomatic sars-cov-2 carriers. Respir Med 169:106026

He X, Lau EHY, Wu P, Deng X, Wang J, Hao X, Lau YC, Wong JY, Guan Y, Tan X, Mo X, Chen Y, Liao B, Chen W, Hu F, Zhang Q, Zhong M, Wu Y, Zhao L, Zhang F, Cowling BJ, Li F, Leung GM (2020) Temporal dynamics in viral shedding and transmissibility of covid-19. Nat Med 26:672-675

Hu Z, Song C, Xu C, Jin G, Chen Y, Xu X, Ma H, Chen W, Lin Y, Zheng Y, Wang J, Hu Z, Yi Y, Shen H (2020) Clinical characteristics of 24 asymptomatic infections with covid-19 screened among close contacts in nanjing, china. Sci China Life Sci 63:706-711

Jin CC, Zhu L, Gao C, Zhang S (2020) Correlation between viral rna shedding and serum antibodies in individuals with coronavirus disease 2019. Clinical microbiology and infection: the official publication of the European Society of Clinical Microbiology and Infectious Diseases

Mazzoni A, Salvati L, Maggi L, Capone M, Vanni A, Spinicci M, Mencarini J, Caporale R, Peruzzi B, Antonelli A, Trotta M, Zammarchi L, Ciani L, Gori L, Lazzeri C, Matucci A, Vultaggio A, Rossi O, Almerigogna F, Parronchi P, Fontanari P, Lavorini F, Peris A, Rossolini GM, Bartoloni A, Romagnani S, Liotta F, Annunziato F, Cosmi L (2020) Impaired immune cell cytotoxicity in severe covid-19 is il-6 dependent. J Clin Invest 130:4694-4703

Ni L, Ye F, Cheng ML, Feng Y, Deng YQ, Zhao H, Wei P, Ge J, Gou M, Li X, Sun L, Cao T, Wang P, Zhou C, Zhang R, Liang P, Guo H, Wang X, Qin CF, Chen F, Dong C (2020) Detection of sarscov-2-specific humoral and cellular immunity in covid-19 convalescent individuals. Immunity 52(971-977):e973

Padoan A, Sciacovelli L, Basso D, Negrini D, Zuin S, Cosma C, Faggian D, Matricardi P, Plebani M (2020) Iga-ab response to spike glycoprotein of sars-cov-2 in patients with covid-19: A longitudinal study. Clin Chim Acta 507:164-166

Rosen HR, Golden-Mason L (2019).Control of hcv infection by natural killer cells and macrophages. Cold Spring Harb Perspect Med

Suthar MS, Zimmerman MG, Kauffman RC, Mantus G, Linderman SL, Hudson WH, Vanderheiden A, Nyhoff L, Davis CW, Adekunle O, Affer M, Sherman M, Reynolds S, Verkerke HP,
Alter DN, Guarner J, Bryksin J, Horwath MC, Arthur CM, Saakadze N, Smith GH, Edupuganti S, Scherer EM, Hellmeister K, Cheng A, Morales JA, Neish AS, Stowell SR, Frank F, Ortlund E, Anderson EJ, Menachery VD, Rouphael N, Mehta AK, Stephens DS, Ahmed R, Roback JD, Wrammert J (2020) Rapid generation of neutralizing antibody responses in covid-19 patients. Cell Rep Med 1:100040

Tang G, Yuan X, Luo Y, Lin Q, Chen Z, Xing X, Song H, Wu S, Hou H, Yu J, Mao L, Liu W, Wang F, Sun Z (2020) Establishing immune scoring model based on combination of the number, function, and phenotype of lymphocytes. Aging (Albany NY) 12:9328-9343

Tay MZ, Poh CM, Renia L, MacAry PA, Ng LFP (2020) The trinity of covid-19: Immunity, inflammation and intervention. Nat Rev Immunol 20:363-374

Thevarajan I, Nguyen THO, Koutsakos M, Druce J, Caly L, van de Sandt CE, Jia X, Nicholson S, Catton M, Cowie B, Tong SYC, Lewin SR, Kedzierska K (2020) Breadth of concomitant immune responses prior to patient recovery: a case report of non-severe covid-19. Nat Med 26:453-455

Wang X, Xu H, Jiang H, Wang L, Lu C, Wei X, Liu J, Xu S (2020) The clinical features and outcomes of discharged coronavirus disease 2019 patients: a prospective cohort study. QJM Monthly J Assoc Phys 113:657-665

Wolfel R, Corman VM, Guggemos W, Seilmaier M, Zange S, Muller MA, Niemeyer D, Jones TC, Vollmar P, Rothe C, Hoelscher M, Bleicker T, Brunink S, Schneider J, Ehmann R, Zwirglmaier K, Drosten C, Wendtner C (2020) Virological assessment of hospitalized patients with covid-2019. Nature 581:465-469

Zhang C, Wang XM, Li SR, Twelkmeyer T, Wang WH, Zhang SY, Wang SF, Chen JZ, Jin X, Wu YZ, Chen XW, Wang SD, Niu JQ, Chen HR, Tang H (2019) Nkg2a is a nk cell exhaustion checkpoint for hcv persistence. Nat Commun 10:1507

Zhang X, Tan Y, Ling Y, Lu G, Liu F, Yi Z, Jia X, Wu M, Shi B, Xu S, Chen J, Wang W, Chen B, Jiang L, Yu S, Lu J, Wang J, Xu M, Yuan Z, Zhang Q, Zhang X, Zhao G, Wang S, Chen S, Lu H (2020) Viral and host factors related to the clinical outcome of covid-19. Nature 583:437-440

Zheng M, Gao Y, Wang G, Song G, Liu S, Sun D, Xu Y, Tian Z (2020) Functional exhaustion of antiviral lymphocytes in covid19 patients. Cell Mol Immunol 17:533-535

Zhou F, Yu T, Du R, Fan G, Liu Y, Liu Z, Xiang J, Wang Y, Song B, Gu X, Guan L, Wei Y, Li H, Wu X, Xu J, Tu S, Zhang Y, Chen $\mathrm{H}$, Cao B (2020) Clinical course and risk factors for mortality of adult inpatients with covid-19 in wuhan, china: a retrospective cohort study. Lancet 395:1054-1062 